\title{
Hematological parameters in pre chemotherapy breast cancer patients in a tertiary care centre
}

\author{
Smita S. Masamatti ${ }^{1}$, Vijaya $C^{2, *}$ \\ ${ }^{1}$ Associate Professor, ${ }^{2}$ Professor and HOD, Dept. of Pathology, Sapthagiri Institute of Medical Sciences and Research Centre, \\ Bangalore, Karnataka, India \\ *Corresponding Author: \\ Email: vijayachowdapp18@gmail.com
}

\begin{abstract}
Introduction: This study aimed to highlight the degree of derangements of various blood parameters preoperatively in carcinoma breast patients as compared with controls who presented with benign breast disease.

Materials and Methods: This was a descriptive study done among clinically diagnosed breast cancer patients attending the central laboratory, at Sapthagiri Institute of Medical Sciences and Research Centre, Bangalore.

Results: A total number of 51 cases of prechemotherapy carcinoma breast patients along with controls were subjected to hematological investigations. Anemia was noted in $60 \%$ of the cases. The overall mean MCV, MCH, MCHC $(79.01 \pm 5.75 \mathrm{fl}$, $26.54 \pm 2.0 \mathrm{pg}, 32.70 \pm 1.6 \mathrm{~g} / \mathrm{l}$ respectively) were lower than the controls. Mean TLC (7.73 \pm 1.84$)$, RDW (15.18 \pm 2.05$)$ and MPV $(7.9 \pm 0.83)$, platelet count $(3.1 \pm 0.8)$ were seen to be higher than the controls.
\end{abstract}

Conclusion: Breast cancer patients showed deranged hematological parameters as a consequence to the disease.

Keywords: Carcinoma, Prechemotherapy, Prognosis.

\section{Introduction}

Breast cancer (ca) incidence has increased and in India it is around 70-90 per $1,00,000$ population and its prevalence is estimated to be around 2.5 million with over 8, 00,000 new cases. Around 5,50,000 deaths occur every year. Routine investigations such as complete blood count (CBC) test are a prerequisite investigation requested for all cancer patients before any surgery, chemotherapy or radiotherapy.

Various blood parameters and systemic inflammatory markers have been correlated with their prognosis in various malignancies. ${ }^{1}$ Prognostic value of cells like neutrophils, platelets, Mean platelet volume (MPV), platelet-lymphocyte ratio and neutrophil to lymphocyte ratio in patients with advanced and local gastric cancer were found to influence the overall survival of patients. ${ }^{2}$ Prognosis and survival was better in patients with higher lymphocyte count. Similar studies were also done to study the lymphocytes in the peripheral blood of patients with breast cancer in the past. $^{3}$ Therefore novel predictive markers are required to identify high risk cancer patients who may develop metastasis during postoperative surveillance which may permit oncologists to utilize more efficient patient treatment strategies. $^{4}$

The present study is carried out to investigate the degree of derangements of hematological parameters and provide mean values in prechemotherapy breast cancer patients when compared with control subjects.

\section{Materials and Methods}

This was a descriptive study carried among the cytologically diagnosed, consenting, pre chemotherapy patients of carcinoma breasts attending central laboratory of Sapthagiri Institute of Medical Sciences and Research Centre, Bangalore, from the period January 2015 to January 2017. It was one year retrospective and one year prospective study.

All females with benign breast diseases were taken as controls.

Inclusion Criteria: Patients aged $>20$ years diagnosed on cytology with breast cancer.

Patients with breast lumps who are diagnosed as carcinoma breast on FNAC.

Exclusion Criteria: Breast carcinoma patients who have undergone chemotherapy or radiotherapy.

Collection of Samples: A total of $4.5 \mathrm{ml}$ of blood was collected from each patient and control subjects in EDTA bottle for full blood count test and analysis was done on the same day of collection.

Procedure: Full blood count was done by sysmex XN 550 five part analyzer.

\section{Statistical Analysis}

The results of 51 cases and 51 controls were analyzed. Data were analyzed using SPSS version 20.0. The descriptive data were given as means \pm SD, Min and Max. The t-test is used to compare Mean difference between case and control group and $\mathrm{p}$-value is calculated. Interpretation of $\mathrm{p}$-value: If $\mathrm{p}<0.05$, is considered to be statistically significant.

\section{Results}

We noticed significant changes in hematological parameters of breast cancer patients when compared with controls.

The present study reported $100 \%$ female prevalence of breast carcinoma. No cases of male ca breast were noted. All age group ranged from 29 years 
to 82 years, the mean being $53.6 \pm 11.5$ which shows the commonest age of presentation in our locality.

Table 1

\begin{tabular}{|l|c|c|c|}
\hline \multicolumn{1}{|c|}{ Parameters } & Tests & Controls & p-value \\
\hline Hb (Mean \pm SD) & $11.3 \pm 1.6$ & $12.8 \pm 1.2$ & 0.3111 \\
Minimum & 7.4 & 10.4 & \\
Maximum & 14.6 & 16 & \\
\hline PCV(Mean \pm SD) & $31.9 \pm 3.6$ & $35 \pm 3.8$ & 0.3100 \\
Minimum & 28 & 32 & \\
Maximum & 34 & 38 & \\
\hline MCV(Mean \pm SD) & $79.0 \pm 5.7$ & $82.0 \pm 4.0$ & 0.0027 \\
Minimum & 64 & 72 & \\
Maximum & 84 & 88 & \\
\hline MCH(Mean \pm SD) & $26.5 \pm 2.0$ & $29.5 \pm 2.1$ & 0.0001 \\
Minimum & 23 & 26.8 & \\
Maximum & 30 & 34 & \\
\hline MCHC(Mean \pm SD) & $32.7 \pm 1.6$ & $34.4 \pm 1.1$ & 0.0001 \\
Minimum & 30 & 32.6 & \\
Maximum & 36.2 & 36.8 & \\
\hline RDW(Mean \pm SD) & $15.2 \pm 2.1$ & $12.9 \pm 0.8$ & 0.0001 \\
Minimum & 12 & 11 & \\
Maximum & 21.7 & 14.2 & \\
\hline
\end{tabular}

Table 2

\begin{tabular}{|l|c|c|c|}
\hline \multicolumn{1}{|c|}{ Parameters } & Tests & Controls & p-value \\
\hline TLC (Mean \pm SD) & $7737.3 \pm 1845$ & $7135 \pm 1419.8$ & 0.0678 \\
Minimum & 4500 & 4500 & \\
Maximum & 14000 & 9800 & \\
\hline Neutrophil\% (Mean \pm SD) & $65.2 \pm 8.5$ & $61.5 \pm 6.8$ & 0.0170 \\
Minimum & 48 & 45 & \\
Maximum & 86 & 74 & \\
\hline Lymphocyte\% (Mean \pm SD) & $31.8 \pm 7.1$ & $36.4 \pm 6.7$ & 0.0011 \\
Minimum & 14 & 25 & \\
Maximum & 46 & 50 & \\
\hline
\end{tabular}

Table 3

\begin{tabular}{|l|c|c|c|}
\hline Parameters & Tests & Controls & p-value \\
\hline Plt (Lakhs) Mean \pm SD & $3.1 \pm 0.8$ & $2.6 \pm 0.8$ & 0.0021 \\
Minimum & 1.5 & 1.5 & \\
Maximum & 4.6 & 3.2 & \\
\hline MPV (Mean \pm SD) & $7.9 \pm 0.8$ & $7.3 \pm 0.7$ & 0.0001 \\
Minimum & 6.2 & 6.0 & \\
Maximum & 9.2 & 8.7 & \\
\hline
\end{tabular}

\section{Discussion}

At present it is estimated that breast cancer is responsible for $>1,300,000$ cases and 450,000 deaths annually worldwide. ${ }^{5}$ With the recent advances in treatment modalities and early detection, breast cancer mortality was reduced by $34 \%$ from 1990 to $2010 .^{6}$ Hence there is a need for simple, reliable and non invasive prognostic biomarker to enable clinicians to perform risk evaluation in these patients before or during the treatment process. ${ }^{7}$

Routine blood tests such as $\mathrm{CBC}$ is used frequently by clinicians to support the work up of diagnosis of several diseases such as anemias, acute infection, allergic disorders, malignancies and immunological disorders, pre operative evaluations and health screening. ${ }^{8}$ Breast carcinoma predominantly affects females as noticed in this study and many other previous studies. ${ }^{9}$ It is estimated that $1 \%$ of breast cancer develops in males. ${ }^{10}$ Olumole et $\mathrm{al}^{11}$ reported $3.9 \%$ prevalence of breast cancer amongst males in Nigeria. The prognosis of breast cancer remains the same as that of females. ${ }^{12}$

A total of 51 cases of carcinoma breast were included in this study who presented to Sapthagiri 
institute of medical sciences and research centre, Bangalore, India. Mean age of presentation was $53.6 \pm 11.5$ in ca breast patients in our locality. None of the patients were younger than 20 years of age. Inekwaba $^{13}$ also showed that majority of the cases around $70 \%$ of breast cancers in Nigeria were between 26-50 years with a peak age range of 36-45 years.

The present study reported anemia in $60 \%$ of the cases when compared with that of the controls using Hemoglobin $(\mathrm{Hb})$ and packed cell volume (PCV). This could be compared with the studies done by Akibami ${ }^{9}$ and Kirshner ${ }^{14}$ who reported anemia in prechemotherapy breast cancer patients using PCV. They also had divided the patients into different stages clinically and compared the degree of anemia in each stage. This categorization could not be made in our study as ours was both prospective and retrospective study.

The various red blood cell indices such as mean corpuscular volume (MCV), mean corpuscular hemoglobin $(\mathrm{MCH})$, mean corpuscular hemoglobin concentration (MCHC) of cases were lower than the controls while the mean red cell distribution width (RDW) i.e. the coefficient of variation of RBCs anisocytosis was higher in patients of ca breast as compared with the controls. This is in agreement with studies done by Daniel, ${ }^{15}$ Amrit Pal, ${ }^{16}$ Sa Ufelle ${ }^{17}$ etc. Rabia Farooq ${ }^{18}$ also reported abnormal hematological parameters in gastric cancer patients. The cause of low hemoglobin $(\mathrm{Hb})$ could be associated to anemia of chronic disorder. Anemia could be due to hemorrhage or due to with iron deficiency anemia. If the mass is ulcerating, then it is evidenced by lower MCV, $\mathrm{MCH}$, MCHC and a higher RDW when compared with the controls. Nutritional anemia can be associated with anorexia in these patients. Metastases to the bone marrow in these patients are generally the cause for suppression of erythropoesis. Infection in fungating malignancy may be associated with RBC hemolysis (anemia) and leucocytosis.

Many previous studies have also shown that the neutrophil lymphocyte ratio (NLR) could provide a prompt representation of the state of inflammation, which might plays an important role in tumor growth, progression, invasion and metastasis. Many inflammatory factors such as pre operative C-reactive protein, human epidermal growth factor receptor 2 (HER2), interleukin 6 are associated with breast carcinoma prognosis. ${ }^{19}$

Mean WBC counts, neutrophil \% of cases were slightly higher than that of the controls because of the fact that all neoplasms of all types are associated with neutrophilia. There may be even a lymphovasular invasion leading to demargination of tumour cells which occupy the vascular spaces. The principle mechanism of tumour immunity is killing of tumour cells by CD8+ cytotoxic T-lymphocytes. The natural killer cells destroy the tumour cells without prior sensitization. Many tumours down regulate expression of class 1 major histocompatability complex (MHC) molecules as a way of evading immunity. Hence lymphocyte count may therefore be depressed or increased. ${ }^{9}$ Present study showed the mean lymphocyte $\%$ was reduced when compared with the normal controls.

Previous literature showed that high platelet counts are associated with later stage, higher risk of recurrence and metastasis in many types of malignancies. Ovarian cancer, renal cell cancer, gastric cancer and colorectal malignancy which were associated with thrombocytosis had poorer prognosis. ${ }^{20}$ Mean platelet count of the cases was also higher than that of control. The cause for this may be reactive thrombocytosis which is seen in malignancy patients as a result of cancer induced anemia. A negative feedback effect on erythropoietin production in patients of cancer breast as a result of anemia could be responsible for thrombocytosis. Thrombopoietin and erythropoietin has a similar structure while Thrombopoietin is considerably bigger than the former, has similarity at the N-terminal region. ${ }^{21}$ Hence were recognized that thrombocytosis is associated with anemia of chronic diseases and several types of anemias. Bone marrow metastasis may also be associated with defective thrombopoesis leading to malignancy induced thrombocytopenia. So thrombocytopenia and thrombocytosis may therefore be associated with malignancy depending on the scenario. ${ }^{21}$ However, Ufelle et $\mathrm{al}^{17}$ study found that platelet levels were higher in control group than the pre and post chemotherapy breast cancer patients.

\section{Conclusion}

To conclude, our study showed increased inflammatory parameters (MPV, RDW, Neutrophil count etc) of complete blood counts in carcinoma breast patients as a consequent to the disease when compared with the controls which may be a useful guide for the oncologists for further treatment. However further studies with larger sample size are required to confirm the findings of the present study.

\section{References}

1. Shrivastava S, Singh N, Nigam AK, Chandel SS, Shrivastava R, Kumar S. Comparative study of hematological parameters along with effect of chemotherapy and radiotherapy in different stages of breast cancer. Int J Res Med Sci. 2017;5:311-5.

2. Aliustaogh M, Bilici A, Ustaalioglu BB, et al. The effect of peripheral blood values on prognosis of patients with locally advanced gastric cancer before treatment. Med Oncol. 2010;27:1060-5.

3. Bainbridge ET, Ford CH, Newman CE. Total lymphocyte counts in breast cancer. Lancet. 1978;1:1203-4.

4. Mantas D, Kostakis ID, Machairas N, Markopoulos C. White blood cell and platelet indices as prognostic markers in patients with invasive ductal breast carcinoma. Onco Lett. 2016;12(2):1610-1614. 
5. Cancer genome atlas network: Comprehensive molecular portraits of human breast tumours. Nature. 2012;490:6170.

6. DeSantis C, Ma J, Bryan L, Jemal A. Breast cancer statistics 2013. CA Cancer J Clin. 64:62-62.

7. Zhang P, Zong Y, Liu M, Tai Y, Cao Y, Hu C. Prediction of outcome in breast cancer patients using test parameters from complete blood count. Mol Clin Oncol. 2016;4(6):918-924.

8. Oday Ali Liqaa. Study effect of Breast Cancer on Some Hematological and Biochemical Parameters in Babylon Province, Iraq. IOSR Journal of Pharmacy and Biological Sciences. 2014;9(3):20-24.

9. Akinbami A, Popoola A, Adediran A, Dosunmu A, Oshinaike O, Adebola P et al. Full blood count pattern of prechemotherapy breast cancer patients in Lagos, Nigeria. Caspian J Intern Med. 2013;4(1):574-9.

10. Korde LA, Zujewski JA, Kamin L et al. Multidisplinary meeting on breast cancer. Summary and research recommendations. J Clin Oncol. 2010;28:2114-22.

11. Oluwole SF, Fadiran OA, Odesanmi WO. Disease of breast in Nigeria. Br J Surg. 1987:74:582-5.

12. Gomez-Raposo C, Zambrana Tever F, Sereno Moyano M, Lopez Gomez M, Casado E. Male breast cancer. Cancer Treat Rev. 2010;36:451-7.

13. Ihekwaba FN. Breast cancer in Nigeria. Br J Surg. 1992;79:771-5.

14. Kirshner J, Hatch M, Hennessy DD, Fridman M, Tannous RE. Anemia in stage II and III Breast cancer patients treated with adjuvant doxorubicin and cyclophosphamide chemotherapy. Oncologist. 2004;9:25-32.

15. Boehm DU, Lebrecht A, Schmidt M, Siggelkow W, Lindner C, Litz A et al. Prognostic impact of hemoglobin levels in breast cancer. Anticancer Res. 2007;27(2):12236.
16. Rana AP, Kaur M, Zonunsanga B, Puri A, Kuka AS. Preoperative peripheral blood count in breast carcinoma: Predictor of prognosis or a routine test. Int J Breast Cancer. 2015;964392.

17. SA Ufelle, EO Ukaejiofo, EE Neboh, PU Achukwu, EJ Ikekpeazu, IC Maduka et al. Some haematological parameters in pre- and post-surgery breast cancer patients in enugu, Nigeria. Int J Cur Bio Med Sci. 2012;2(1):188190.

18. Rabia Farooq, Arif Akbar Bhat, Hilal Ahmad Wani, Nisar Ahmad Naikoo, Hamid Bashir, Shajrul Amin, Bashir Ahmad Ganaie, Sabhiya Majid. Role of hematological parameters in diagnosis and prognosis of gastric carcinoma in Kashmir, India. Int Res J Pharm. 2013;4(8):134-137.

19. Wei B, Yao M, Xing C, Wang W, Yao J, Hong Y et al. The neutrophil lymphocyte ratio is associated with breast cancer prognosis: an updated systematic review and meta-analysis. Onco Targets Ther. 2016;8(9):5567-75.

20. Okuturlar Y, Gunaldi M, Tiken EE, Oztosun B, Inan YO, Ercan T, et al. Utility of peripheral blood parameters in predicting breast cancer risk. Asian Pac J Cancer Prev. 2015;16(6):2409-12.

21. Hoffbrand AV, Lewis MS, Tuddenham ED. Postgraduate heamatology, Oxford University Press, $4^{\text {th }}$ edition, 2001;pp19.

How to cite this article: Masamatti SS, Vijaya
C. Hematological parameters in pre
chemotherapy breast cancer patients in a tertiary
care centre. J Diagn Pathol Oncol.
$2018 ; 4(3): 237-240$.

